\title{
A Literature Review of Consumption Embarrassment and Prospects
}

\author{
Yiting Li*, Defeng Yang, Han Zhou \\ School of Management, Jinan University School, Guangzhou, China \\ Email: *liyiting_2017@163.com
}

How to cite this paper: Li, Y.T., Yang, D.F. and Zhou, H. (2018) A Literature Review of Consumption Embarrassment and Prospects. American Journal of Industrial and Business Management, 8, 686-699. https://doi.org/10.4236/ajibm.2018.83046

Received: February 27, 2018

Accepted: March 24, 2018

Published: March 27, 2018

Copyright $\odot 2018$ by authors and Scientific Research Publishing Inc. This work is licensed under the Creative Commons Attribution International License (CC BY 4.0).

http://creativecommons.org/licenses/by/4.0/

\begin{abstract}
Consumers will have a temporary feeling of embarrassment, when they experience unexpected events, which will influence consumers' cognition and behavior. This paper focused on embarrassing emotion in consumption and reviewed the related literature. We expound the concept of consumption embarrassment and distinguished the similar concepts, then summed up antecedents and the outcome variables. The model of consumption embarrassment is concluded on the existing empirical conclusions. Direction of future research is discussed in the end.
\end{abstract}

\section{Keywords}

Consumption Embarrassment, Negative Emotions, Consumer Behavior

\section{Introduction}

Understanding the mechanism of target consumers' decision is the shortest way to improve the marketing chances. Nowadays, it is becoming clear that consumers are becoming more and more emotional. Consumption decisions of them are made by emotion. Marketers should fully recognize and face consumers' sensibility. With the rapid development of Internet technology, the cost of enterprises to implement marketing strategy is lower than before and higher. Especially, emotional marketing becomes the emerging and effective marketing strategy which used by enterprises, such as the application of nostalgia in advertising and fear in the promotion strategy. What bothers businesses, however, is that consumers are sometimes not influenced by these marketing tools and may even act in the opposite direction. Hiring attractive service providers, for example, may cause consumers to experience embarrassment, and create consumers' self-presentation concern. This situation will let consumer refuse to communi- 
cate with service providers [1]. In the process of fitting, it is also possible to bring embarrassment to consumers when they find someone dressing the same products with them, which is perceived as a threat to their identity, leading to higher product disposition [2]. These situations above are academically known as consumption embarrassment. Consumption embarrassment is a temporary state of panic and distress that arises when an individual is unexpectedly or forced to become the focus of another's attention [3] [4]. Those who experience consumption embarrassment will have a higher level of public self-awareness, feeling their identity being threatened. Thus, they will pay more attention to others' evaluations of themselves.

Embarrassment as a kind of independent emotion originates from psychology area, describing self-consciousness of the individual in social intercourse which related to morality. Embarrassment is the result of complex interactions between situations, individual personalities, and real or imaginary audiences. Once the theory is put forward, researchers pay close attention to this concept, and they are aware of its importance to individual development. Embarrassment is widely used in many fields such as education, counseling and treatment. Among these varieties of application, Darren formally put forward the concept of "consumption embarrassment" in the consumer behavior domain [3]. He explores the situational factors and consumer traits that affect the consumer's embarrassing emotions. With the marketing theoretical concept and emotional marketing being valued, we believe that paying enough attention on embarrassing emotion in the consumption environment becomes a key element of marketing success. On the one hand, the marketers will not take action to, initiatively, use the strategy causing the consumer's embarrassment emotion. But in the daily consumption situation, the consumer's awkward sentiment is widespread. Consumer's decision is influenced not only by product objective attribute such as price, quality, brand, but also by consumer's emotion in consumption situation. On the other hand, consumers' embarrassment is different from other negative emotions as a transient emotional experience, which has a unique influence on consumer cognition and behavior. The individual perception of embarrassment in a consumer environment is often subtle and hidden, and the embarrassment of consumers may prompt consumers to try to respond indirectly through specific product choices or purchase decisions [1] [5]. To sum up, paying attention to consumption embarrassment in consumer behavior has a broad application prospects and practical significance. This paper mainly focus on embarrassing emotion in consumption and review the related literature.

The article is organized as follows: Firstly, we expound the concept of the consumption embarrassment and distinguish the similar concepts. Then sum up antecedents and the outcome variables. Furthermore, the model of consumption embarrassment is concluded on the existing empirical conclusions. On the basis of this, the future research direction is prospected, hoping to provide enlightenment for the subsequent consumers' research. 


\section{The Core Viewpoints and Related Concepts}

\subsection{Consumption Embarrassment}

To understand consumption embarrassment, the first thing is to know about embarrassing emotion. Embarrassment as a human emotion is known to be very pervasive in everyday life [6]. Goffman describes "embarrassment" is an emotion that results from a breakdown in everyday social encounters [7]. According to Goffman, embarrassment occurs in social interactions when unwanted events intervene and result in a loss of composure and the ability to participate in an encounter. However, early studies of embarrassment suggest that embarrassment is not an independent emotion, but a type of shame. So there is no "embarrassment" in the classic mood classification before the 1970s. Embarrassment as an independent emotion first appeared in the of Ekman's theory of emotional classification. Ekman indicates that embarrassment, like shyness and guilt, is a kind of independent emotion after the emergence of self-consciousness, and has its unique characteristics and development rules.

Generally speaking, when an individual has inappropriate behavior, the individual will be considered defective and experience a temporary loss of self-esteem. It will lead to the emergence of embarrassing emotions. Sattler believes that individuals are embarrassed when they receive unexpected attention, such as social etiquette, clothing, and so on. This concern threatens the individual's self-expression and situational self-esteem, causing an individual's discomfort and creating embarrassment. Edelman describes embarrassment as a social phobia [4]. He argues that embarrassment is a "cause of uncomfortable mental state, which has a devastating effect on social interaction. Edelmann points out that this interaction must include bystanders and imaginary ones, even if it happens privately. Sharkey suggests that embarrassment is seen as the result of the difference between an individual's ideal identity and his manifest identity [8]. Silver and Sabini have described embarrassment as an unpleasant, uneasy, powerful emotional state. The emotional nature of embarrassment is social interaction and has a moderating effect on social behavior and social interaction. Miller considers embarrassment to be a disgusting, humiliating state, a shame and chagrin in the context of a public social dilemma [9]. Miller once described embarrassment as: when an individual experiences an event that increases his or her likelihood of being subjected to an unwanted assessment, it can come from a real audience, or only from an individual's imaginary audience, a panic, clumsy, distress-stricken, acute state of an individual that is embarrassing. One striking feature of embarrassment, he argues, is that individuals feel fooled and humorous, not more deeply blamed. As shown in Table 1, the definitions of embarrassment are derived from the conclusions of the relevant empirical literature.

The above definition describes the different aspects of embarrassment, but both emphasize that the individual's attention to his image in the eyes of others. The definition of embarrassment can be summed up to two points: 1) Being accidentally noticed in a social situation can lead to embarrassment; 2) An individual's 
Table 1. Definition of embarrassment.

\begin{tabular}{|c|c|}
\hline Researchers & Definition \\
\hline Goffman (1956) & an emotion that results from a breakdown in everyday social encounters. \\
\hline Sattler (1981) & individuals feel embarrassed when receive unexpected attention \\
\hline Edelman (1987) & $\begin{array}{l}\text { an "uncomfortable psychological state that has a devastating effect on social } \\
\text { interaction." }\end{array}$ \\
\hline Sharkey (1992) & $\begin{array}{l}\text { result of the difference between an individual's ideal identity and his manifest } \\
\text { identity }\end{array}$ \\
\hline Silver (2012) & An unpleasant, restless, powerful emotional state. \\
\hline Miller (2001) & $\begin{array}{l}\text { a repulsive, humiliating state of shame and frustration in the context of public } \\
\text { social dilemmas. }\end{array}$ \\
\hline
\end{tabular}

social misconduct causes embarrassment to the individual。Building on Goffman's work, embarrassment has more recently been described as a short-lived negative psychological response [10]. Embarrassment involves a threat to an individual's presented self-resulting from unwanted evaluations from real or imagined audiences, and it is considered to play a powerful role in regulating social behavior [11].

Consumers also experience embarrassment in the consumption. Past research has established the widespread prevalence of embarrassment in consumption domain. Dahl formally puts forward the concept of "consumption embarrassment" [3]. He uses the method of empirical research to measure the embarrassment of consumers, and discusses the situational factors and consumers' characteristics which affect consumption embarrassment. He define consumption embarrassment during purchase as "an aversive and awkward emotional state following events that increase the threat of unwanted evaluation from a real or imagined social audience." Verbeke has made a measurement of the sales staff who felt embarrassed in sell financial services [12]. Results suggest that embarrassment in personal marketing can lead to protective reactions (i.e., avoidance), which negatively impact marketers' performance and marketing interactions. If salespeople planned to get new customers and maintain long-term customer relationships, they would more likely to take protective action in embarrassing situation. Grace studied the embarrassing emotions experienced by consumers in the process of receiving services [13]. As to the causes of embarrassment in service, consumers will be influenced by service providers and others consumers present. When consumers experience criticism, clumsy behavior, invasion of privacy, or have inappropriate image before others, they will feel embarrassed.

\subsection{Consumption Embarrassment, Guilt and Shame}

In earliest studies, researchers argued that embarrassment is essentially the same as shyness, but weaker in intensity than shyness. Later empirical studies have proved the differences between embarrassment and shyness and guilt. Embarrassment is a form of social anxiety closely related to, but also distinct from, 
shyness, audience anxiety, and shame.

Typical antecedent conditions of embarrassment is the violation of social customs, which increases the probability of individual social exposure, such as loss of control over the body, exposure to privacy, clumsy communication, and social concerns that violate expectations [14]. Yet antecedent conditions of shame is that expectation cannot be achieved successfully and others [15]. The expectation originates from individual oneself or others. For example, failure to accomplish tasks related to achievement, hurting others' feelings, or violating the ideal self can cause a sense of shame. Guilt is thought to be the reaction of one's internalized conscience to a breach of one's personal standards and thus may be felt when one is entirely alone, such as cheating, stealing, lying, ignoring your responsibilities [16]. Embarrassment will let individuals have feelings of funny, clumsy, stupid, tense, and surprised. When individuals experience embarrassment, they may have intention to laugh, hide or avoid. The feeling of shame includes immorality, isolation from others, lasting anger and disgust. Individuals also have an intention of apologizing [16]. For guilt, individuals will experience the following feelings: a strong sense of compassion for others, awareness of others' feelings, and a motivation to relieve pain by acting frankly and apologizing [17].

\section{Antecedent Variables of Consumption Embarrassment}

There are many factors that cause consumption embarrassment. Scholars in psychology domain have a great deal of discussion on the causes of embarrassment, including self-esteem model, the drama model, the model of contrary to others' expectation and the model of unwanted exposure [18]. These model explains some typical embarrassing situations: 1) Self-esteem model emphasizes embarrassment is caused by assessment of one's identity, such as a fool on a date; 2) The drama model indicates that the feeling of embarrassment comes from the social disorder caused by a person's inability to play a role in society, such as being reminded by a friend to payback in public; 3) The model of contrary to others' expectation emphasizes the effect of others' evaluation on embarrassing emotion, such as forgetting words in a speech; 4) The model of unwanted exposure argues that when individuals are reluctant to be exposed to public situations, they feel embarrassed, such as falling in the street on a rainy day. From the cause of embarrassment, this mood has two characteristics: Violation and Social Presence.

In consumer behavior domain, consumption embarrassment may occur at all stages of the process: before, during, and after the purchase. Dahl points out that consumption embarrassment mainly occur during purchase [3]. For instance, when a consumer chooses the product by removing it from the shelf with an intention to purchase In a comprehensive way, the influence factors of consumers' embarrassment can be divided into three aspects: products, consumption environment and consumer's psychological characteristics. 


\subsection{Products}

According to Iacobucci particular type of products acts as the source of embarrassment. The properties of certain products may cause embarrassment to consumers. Sarka points out that embarrassing product class can potentially elicit embarrassment [19]. If consumers think that the purchase of products like condoms are difficult to deal with in a social context, they can feel embarrassed. Contradicting the consumer's desired public identity is the main cause of embarrassment consumption when the purchase is observable. For example, consumers may feel embarrassed to purchase condoms in public if they believe others will infer they are promiscuous [3]. In addition, the product mix purchase will also be embarrassed by consumers. Different product mix can make consumers have negative connection, because additional purchases exacerbate anticipated embarrassment to the extent that they are perceived to complement the undesired identity communicated during purchase. In Blair's experiments, he found that purchasing anti-diarrheal medicine was expected to be more embarrassing when respondents were also purchasing underwear. This shows that product attributes can cause embarrassment. And the range of product class that may cause consumption embarrassment is wide, such as hearing aids and undergarments of adults. Therefore, marketers who aim to persuade customers to buy such products need to help customers overcome or cope with this embarrassing feeling.

Another factor involving product is familiarity. A consumer who is familiar with the purchase of an embarrassing product will experience a lower level of embarrassment than a consumer who is not familiar with making such a purchase [3]. Because of familiarity with purchasing a product, consumer will not experience the embarrassment that results from the reduction of the amount of uncertainty in a future. If consumers were buying embarrassing products for the first time, they may feel that some people paid attention to them [20]. However, Gilovich found consumer felt less embarrassed in the follow-up study. That is, when subjects become familiar through the habituation process, they estimate less observation from a social audience.

\subsection{Consumption Environment}

Consumption can take place in a private or public context [21], that is to say the presence or absence of others influences consumer perception. Embarrassment would occur if the purchaser is aware of a social presence (either real or imagined) and if the purchase or the events surrounding the purchase communicate undesired information about oneself [4]. Comparing to the situation that a real or imagined social presence is absent, consumer will experience a higher level of embarrassment during an embarrassing product purchase when a real or imagined social presence exists [3]. Argo posits that "impact of a social presence's social forces increases as a power function such that the greatest influence will arise when the social presence is large (vs small), is in close (vs far) proxim- 
ity, or is high in source strength" [22].

The Role of Social Presence in the shopping environment mainly consist of includes salesperson and other consumers. Companies always hire good-looking salesperson to attract consumers. However, Wan's research found that fewer consumers made a purchase of the embarrassing product when the salesperson was attractive than when he was not. Consumers interacted less often with the attractive salesperson than with the average-looking one and, if they interacted, spent relatively less time doing so [1]. Embarrassing consumption is likely to endanger people's positive self-image in social context, because they want to make a good impression on others in the situation are attractive. That's why consumers will reduce interaction with attractive sales-providers in an embarrassing consumption situation.

Other consumers are another vital factor. Consumers may evaluate a product more negatively when their consumption aligns with an attractive referent other than when it does not align [5]. Dahl describes that when an attractive social referent is consuming a product, the consumer who must also be actively consuming the same product will have negative comparisons and thus experience the embarrassment. For instance, trying on a target shirt in the same fitting room will feel awkward. The embarrassment caused by "dress same" may pose a threat to consumers' self-identity [23]. As compared to non-identity symbolic products, the accidental similarity of the identity costume leads to a higher feeling of embarrassment and higher disposition of the product.

Consumption environment, especially the public context, may result in consumption embarrassment. Embarrassment occurs when individual is in a social context, and perceives getting evaluated by other people present in the setting. Products placement surrounding embarrassing product may let consumer feel embarrassed. Consumers who plan to buy condoms say that the counter is the least favorite position, which makes them feel embarrassed [24]. Argo indicates that mannequin placement in the consumption environment is demonstrated to have negative implications for some consumers [21]. As mannequins signal the normative standard of beauty and consumers may believe they fail to meet this standard, these consumers become threatened by the beauty standard when exposed to a mannequin. As a result, consumers experience embarrassment in the face of beautiful mannequins.

Unexpected situations in the context of consumption can also bring embarrassing emotions. For instance, the amount of credit that was accidentally found at checkout was not enough [25]. Bonnici discussed the embarrassment aroused when using discount coupons. As regards the relation between embarrassing emotions and product use [26].

\subsection{Consumers' Characteristics}

Consumption embarrassment is not only affected by external factors such as product and shopping environment, but also related to consumers' own psycho- 
logical characteristics [27]. Thus, the individual level factor also receives the scholar's active attention. Consumer's characteristics mainly includes two aspects: the demographic characteristic and the psychological characteristic.

Consumption embarrassment is influenced by age, gender and other demographic characteristics. Women are more likely to feel embarrassed than men [24]. Gebhardt's study shows that seventy percent of women indicated it was embarrassed to buy sexual products at the counter, while only fifty percent of men felt embarrassed. It means women prefer less sexual and private contexts. People always cope with the embarrassment of embarrassing products using a variety of tactics, such as buying from a sales clerk of the same gender or buying additional products. However, women prefer different coping mechanisms than men when acquiring embarrassing products [28].

In terms of psychological characteristics, self-esteem is an important influence factor. Consumers with different levels of self-esteem will have distinct coping strategies when they feel embarrassed, resulting in differences in their preference changes related to brand conspicuousness [28] [5]. When feeling embarrassed, consumers with low self-esteem are more likely to have increased motivation to avoid social attention to the self in general to repair their self-image. Individuals low in body esteem who try on a product will evaluate it more negatively when exposed to a referent other who is also actively consuming the focal product. Those individuals high in body esteem evaluated the product equally high regardless of the referent other's consumption behavior. Furthermore, anxiously attached individuals are more prone to be embarrassed compared to the individuals adopting secure and avoidant attachment styles [18].

Through the above analysis it is not difficult to find that the impact of consumer embarrassment is both psychological and behavioral aspects. Overall, the factors that influence on consumption embarrassment involve three levels: products, consumption environment and consumer's psychological characteristics. These factors can lead to consumer embarrassment, thus forming a progressive continuous process.

\section{Influence of Consumption Embarrassment}

The extensive previous work on embarrassment describes it as a negative emotion. When consumers are embarrassed in the consumption situation, they will appear blush, stutter and a series of negative physiological reaction if they cannot effectively deal with this kind of negative psychological state of disgust [11]. Because embarrassment involves a threat to their public self-view, individuals generally display different behavioral tendencies to cope with the negative emotion [3]. Thus, consumers have motivation to use coping tactics to mitigate negative feelings.

In a comprehensive view, the existing research about the impact of consumer embarrassment mainly concentrates on the consumer's purchase decision. Consumers who experience the embarrassment may take one of the four strategies: 
abandoning purchase, delaying purchase, additional purchase and compensation purchase.

\subsection{Abandoning Purchase}

Consumption embarrassment is a negative emotion that arises from consumption environment in which people worry about potential damage to their social self-image. To weaken the negative impact, consumers may choose to escape the embarrassing situation and may therefore avoid embarrassing purchases altogether [27]. Consistent with this idea, consumers have been shown to avoid products that signal undesired identities even when doing so reduces enjoyment. Furthermore, when consumers experience the embarrassment, they will reduce the interaction with the attractive service providers in order to maintain their image [1]. When a self-presentation concern is made salient, consumers react less positively to highly attractive providers than to less attractive ones. This concern can be influenced by chronic social anxiety or can be aroused by unrelated experiences that consumers have before being exposed to the service interactions. Thus, people try to avoid potentially embarrassing situations [29]

\subsection{Delaying Purchase}

When individuals cannot avoid the threat of embarrassment entirely, they often attempt to "save face" by minimizing or explaining away the embarrassing behavior. This so-called "facework" is a coping mechanism intended to protect and, if necessary, restore the desired public identity [30]. In the context of embarrassing purchases, prior research has identified a number of such face-saving strategies. For example, consumers may shop in stores that are less crowded to reduce the likelihood that there will be others upon whom to make an undesired impression. Similarly, consumers may avoid asking store employees for help and may wait until other shoppers leave the aisle before physically acquiring an embarrassing product.

\subsection{Additional Purchase}

When consumers buy embarrassing products, they often buy additional products to cover up their real purchases purpose [27]. Prior research has documented that certain purchases are sufficient to elicit embarrassment [30] [31]. Given the aversive nature of this emotion, it is not surprising that consumers employ a repertoire of coping strategies such as Mellish's strategy of purchasing additional non-embarrassing products. Sean indicates that non-embarrassing products also bring Consumption embarrassment. Shopping basket composition is an important factor in purchase embarrassment and additional purchases attenuate anticipated embarrassment to the extent when they are perceived to counterbalance the undesired identity communicated during purchase [32].

\subsection{Compensation Purchase}

People who feel embarrassed may be motivated to restore the positive image that 
has been tarnished by the embarrassing event. Compared with the direct compensatory coping strategies, the previous study of the behavioral consequences of embarrassing emotions, consumers will indirectly deal with the negative effects of embarrassment by buying products that are highly correlated with attractiveness [33]. Individuals can symbolically employ these coping strategies by choosing commercial products that literally either hide their face (e.g., sunglasses) or repair it (e.g., restorative cosmetics).

Research on mood-repair processes has indicated that individuals are generally motivated to reduce or eliminate the negative feelings they experience and that they use indirect means of doing so when the actual cause of their feelings cannot be immediately eliminated [34] [35].

In general, consumers dislike embarrassment situations. Consumption embarrassment can cause discomfort feeling to consumers, and this discomfort feeling prompts consumers to seek solutions to eliminate embarrassment. Existing research finds that consumer embarrassment is a public, negative emotion that consumers often use coping tactics. Based on the existing empirical research, we constructs a model of consumption embarrassment integration. As shown in Figure 1, all variables and arrows are derived from the conclusions of the relevant empirical literature.

\section{Future Research}

Scholars have long been interested in embarrassing research. Early studies researches mainly focus on the theoretical exploration. More and more empirical studies have emerged in the past 10 years, while the literatures in consumer behavior domain are not very interesting. It is not difficult to find out the research results of consumption embarrassment, which has been mainly concentrating on the conceptual connotation, influencing factors and psychological and behavioral responses of consumers' embarrassment. Undoubtedly, these positive explorations made by scholars are of great significance both in theory advancement and

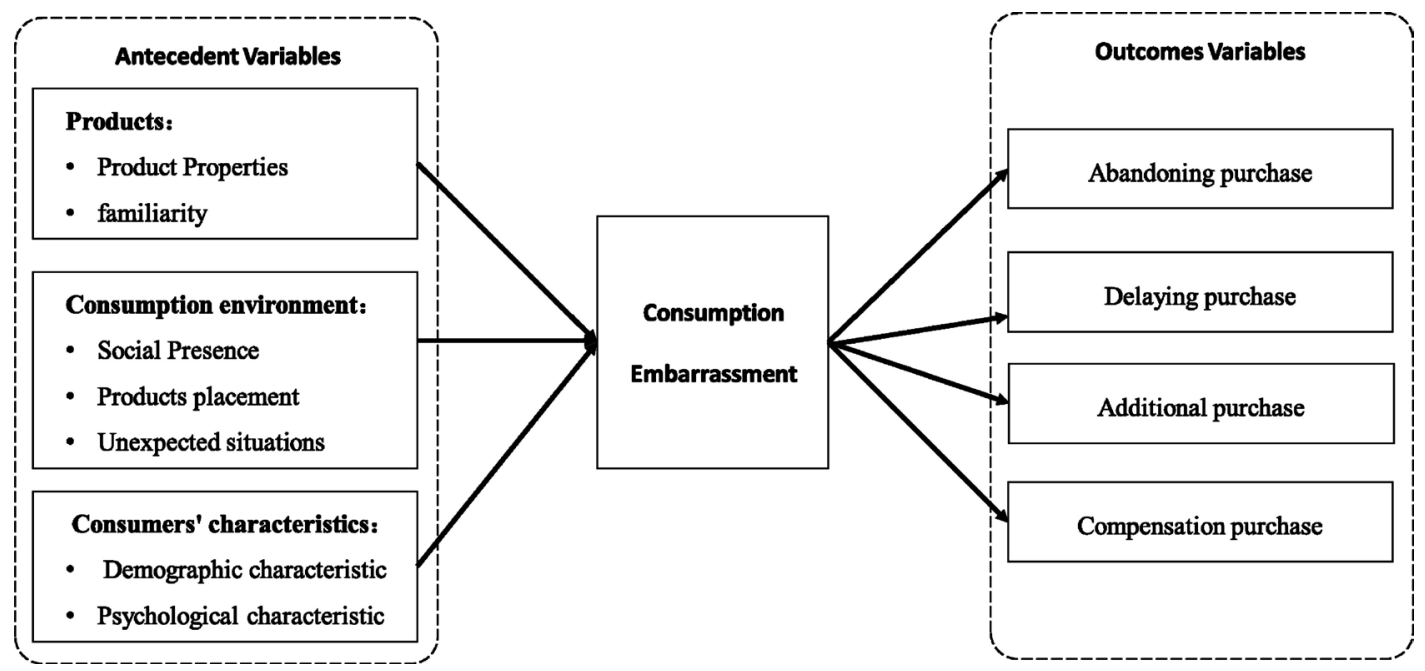

Figure 1. The model of consumption embarrassment integration. 
marketing practice guidance. However, there are still some limitations on the research of consumer's psychological response. Especially the conclusion of empirical research is fragmentary and scattered, and many problems need further discussion. For example, the type of consumer embarrassment has not been discussed. Scholars in psychology domain highlight the importance of empathic embarrassment, however the impact of empathic embarrassment on consumers has not been discussed. Based on the previous analysis and carding, we believe that there will be in the future at least from the following two areas to continue to carry out in-depth research.

\subsection{Context of Consumption Embarrassment}

The extensive previous work on embarrassment describes it as a social emotion within an impression management paradigm [7] [16]. Building upon the earlier work of Goffman, Edelmann argues that embarrassment is a response to threats upon one's public identity or social image that creates a concern for how one is being appraised by others [4]. However, some researches point out that embarrassment may also be a private emotion. Krishna developed a typology of embarrassment with two underlying dimensions-social context (transgression in-public or in-private) and mechanism (appraisal by others or by the self) [36]. Of the four resulting categories, one fits with the dominant "social" view of embarrassment, whereas the other three have aspects of privacy. So will the embarrassment of private situations affect consumers? In this case, will the consumer's attitude towards brand change? Future research could also examine private consumption contexts in which consumption embarrassment would have different impact on products preference.

\subsection{Psychological Mechanism of Consumption Embarrassment}

The existing psychological mechanisms of consumer embarrassment focus on the impression management and social comparison theory. For instance, selfpresentation concerns when an opposite-sex provider is attractive are driven by sexual motives, whereas these self-presentation concerns when a same-sex target is attractive are stimulated by social comparison processes [1]. The extensive previous work on consumption embarrassment holds that consumption embarrassment is caused by the upward comparison. Indeed, it is possible that consumption embarrassment is caused by the downward comparison. For instance, in conspicuous consumption, consumers find that marginal groups show off their favorite brands. Will they be embarrassed?

\section{Funding}

This research was funded by the Natural Science Foundation of Guangdong (2015A030401041).

\section{References}

[1] Wan, L.C. and Wyer, R.S. (2015) Consumer Reactions to Attractive Service Provid- 
ers: Approach or Avoid? Journal of Consumer Research, 42, ucv044. https://doi.org/10.1093/jcr/ucv044

[2] Gong, X.S. and Jiang, J. (2018) The Effect of Incidental Similarity ("Dress Same") on Consumers' Product Disposition Intentions and Its Underlying Mechanism. Acta Psychologica Sinica, 50, 337-348

[3] Dahl, D.W., Manchanda, R.V. and Argo, J.J. (2001) Embarrassment in Consumer Purchase: The Roles of Social Presence and Purchase Familiarity. Journal of Consumer Research, 28, 473-481. https://doi.org/10.1086/323734

[4] Edelmann, R.J., Asendorpf, J.B., Contarello, A., Georgas, J., Villanueva, C. and Zammuner, V. (1987) Self-Reported Verbal and Non-Verbal Strategies for Coping with Embarrassment in 5 European Cultures. Social Science Information, 26. https://doi.org/10.1177/053901887026004008

[5] Dahl, D.W., Argo, J.J. and Morales, A.C. (2012) Social Information in the Retail Environment: The Importance of Consumption Alignment, Referent Identity, and Self-Esteem. Journal of Consumer Research, 38, 860-871.

https://doi.org/10.1086/660918

[6] Miller, R.S. (1996) Embarrassment: Poise and Peril in Everyday Life. Guilford, New York.

[7] Goffman, E. (1956) Embarrassment and Social Organization. American Journal of Sociology, 62, 264-271. https://doi.org/10.1086/222003

[8] Sharkey, W.F. (1992) Use and Responses to Intentional Embarrassment. Communication Studies, 43, 257-275. https://doi.org/10.1080/10510979209368377

[9] Miller, R.S. (2001) On the Primacy of Embarrassment in Social Life. Psychological Inquiry, 12, 30-33.

[10] Metts, S. and Cupach, W.R. (1989) Situational Influence on the Use of Remedial Strategies in Embarrassing Predicaments. Communication Monographs, 56, 151-162. https://doi.org/10.1080/03637758909390256

[11] Miller, R.S. and Leary, M.R. (1992) Social Sources and Interactive Functions of Emotion: The Case of Embarrassment. Studies in Foreign Education, 1, 166-169.

[12] Verbeke, W. and Bagozzi, R.P. (2002) A Situational Analysis on How Salespeople Experience and Cope with Shame and Embarrassment. Psychology \& Marketing, 19, 713-741. https://doi.org/10.1002/mar.10032

[13] Grace, D.A. (2007) How Embarrassing! An Exploratory Study of Critical Incidents Including Affective Reactions. Journal of Service Research, 9, 271-284. https://doi.org/10.1177/109467050700900305

[14] Buss, A.H. (1980) Self-Consciousness and Social Anxiety.

[15] Lewis, M. (1992) Shame: The Exposed Self. Free Press, New York.

[16] Tangney, J.P., Miller, R.S., Flicker, L. and Barlow, D.H. (1996) Are Shame, Guilt, and Embarrassment Distinct Emotions? Journal of Personality \& Social Psychology, 70, 1256-1269. https://doi.org/10.1037/0022-3514.70.6.1256

[17] Sabini, J., Siepmann, J., Stein, J. and Meyerowitz, M. (2000) Who Is Embarrassed by What? Cognition and Emotion, 14, 213-240. https://doi.org/10.1080/026999300378941

[18] Sarkar, J.G. and Sarkar, A. (2017) Investigating Young Customers' Retail Purchase Embarrassment. Marketing Intelligence \& Planning, 35, 111-129. https://doi.org/10.1108/MIP-03-2016-0057

[19] Gilovich, T., Medvec, V.H. and Savitsky, K. (2000) The Spotlight Effect in Social Judgment: An Egocentric Bias in Estimates of the Salience of One's Own Actions 
and Appearance. Journal of Personality \& Social Psychology, 78, 211-222. https://doi.org/10.1037/0022-3514.78.2.211

[20] Wakefield, K.L. and Inman, J.J. (2003) Situational Price Sensitivity: The Role of Consumption Occasion, Social Context and Income. Journal of Retailing, 79, 199-212. https://doi.org/10.1016/j.jretai.2003.09.004

[21] Argo, J.J. and Dahl, D.W. (2017) Standards of Beauty: The Impact of Mannequins in the Retail Context. Journal of Consumer Research, 44, 974-990. https://doi.org/10.1093/jcr/ucx072

[22] Berger, J. and Heath, C. (2007) Where Consumers Diverge from Others: Identity Signaling and Product Domains. Journal of Consumer Research, 34, 121-134. https://doi.org/10.1086/519142

[23] Keltner, D. (1995) Signs of Appeasement: Evidence for the Distinct Displays of Embarrassment, Amusement, and Shame. What the Face Reveals, 68, 441-454. https://doi.org/10.1037/0022-3514.68.3.441

[24] Gebhardt, W.A., Mp, V.D.D., Billingy, N., Carstens, M. and Steenhuis, I. (2011) Preferences for Condom Placement in Stores among Young Dutch Men and Women: Relationships with Embarrassment and Motives for Having Sex. Sexual Health, 9, 233-239. https://doi.org/10.1071/SH11050

[25] Tsao, Y.C. and Chan, S.C. (2011) A Study on Embarrassment Associated with Product Use. Applied Ergonomics, 42, 503-510.

https://doi.org/10.1016/j.apergo.2010.09.010

[26] Bonnici, J., Campbell, D.P., Fredenberger, W.B. and Hunnicutt, K.H. (1997) Consumer Issues in Coupon Usage: An Exploratory Analysis. Journal of Applied Business Research, 13, 31-40. https://doi.org/10.19030/jabr.v13i1.5770

[27] Song, X., Huang, F. and Li, X. (2017) The Effect of Embarrassment on Preferences for Brand Conspicuousness: The Roles of Self-Esteem and Self-Brand Connection. Journal of Consumer Psychology, 27, 69-83. https://doi.org/10.1016/j.jcps.2016.05.001

[28] Arndt, A.D. and Ekebas-Turedi, C. (2017) Do Men and Women Use Different Tactics to Cope with the Embarrassment of Buying Condoms? Journal of Consumer Behaviour, 16, 499-510. https://doi.org/10.1002/cb.1648

[29] Feinberg, M., Willer, R. and Keltner, D. (2012) Flustered and Faithful: Embarrassment as a Signal of Prosociality. Journal of Personality \& Social Psychology, 102, 81-97. https://doi.org/10.1037/a0025403

[30] Keltner, D. and Buswell, B.N. (1997) Embarrassment: Its Distinct Form and Appeasement Functions. Psychological Bulletin, 122, 250-270.

https://doi.org/10.1037/0033-2909.122.3.250

[31] Nichols, B.S., Raska, D. and Flint, D.J. (2015) Effects of Consumer Embarrassment on Shopping Basket Size and Value: A Study of the Millennial Consumer. Journal of Consumer Behavior, 14, 41-56. https://doi.org/10.1002/cb.1500

[32] Blair, S. and Roese, N.J. (2013) Balancing the Basket: The Role of Shopping Basket Composition in Embarrassment. Journal of Consumer Research, 40, 676-691. https://doi.org/10.1086/671761

[33] Dong, P., Huang, X.I. and Wyer, R.S. (2013) The Illusion of Saving Face: How People Symbolically Cope with Embarrassment. Psychological Science, 24, 2005-2012. https://doi.org/10.1177/0956797613482946

[34] Lazarus, R.S. and Folkman, S. (1991) The Concept of Coping. In: Monat, A. and Lazarus, R.S., Eds., Stress and Coping. An Anthology, Columbia University Press, 
New York, 189-206.

[35] Shen, H. and Wyer, R.S. (2008) The Impact of Negative Affect on Responses to Affect-Regulatory Experiences. Journal of Consumer Psychology, 18, 39-48. https://doi.org/10.1016/j.jcps.2007.10.008

[36] Krishna, A., Herd, K.B. and Aydınoğlu, N.Z. (2015) Wetting the Bed at Twenty-One: Embarrassment as a Private Emotion. Journal of Consumer Psychology, 25, 473-486. https://doi.org/10.1016/j.jcps.2015.02.005 